\title{
SINKRETISASI SINRILIK DATU MUSENG DAN MAIPA DEAPATI PADA BUDAYA MASYARAKAT KABUPATEN GOWA
}

\author{
Syncretization of Sinrilik Datu Museng And Maipa Deapati Cultural Comparative \\ Study of Gowa Regency
}

\author{
Andi Hasrianti \\ Sekolah Tinggi Agama Islam Negeri Sorong \\ Jl. Sorong-Klamono KM 17 Klablim Kota Sorong \\ Email: blue_riant@yahoo.co.id
}

Naskah diterima tanggal 15 Januari 2014. Naskah direvisi tanggal 19 Maret 2014. Naskah disetujui tanggal 3 April 2014.

\begin{abstract}
Abstrak
Penelitian ini merupakan penelitian kualitatif yang mengkaji tentang sinkretisme sinrilik Datu Museng dan Maipa Deapati pada budaya masyarakat Kabupaten Gowa. Proses penggabungan dan pengkombinasian unsur-unsur asli dengan unsur-unsur asing ini kemudian memunculkan sebuah pola budaya baru yang dikatakan sinkretis. Fenomena sinkretisasi diarahkan terutama pada sinkretisasi yang terjadi pada sistem kepercayaan, yang memang mengalami perubahan. Perubahan dimaksud yang terjadi adalah setelah masyarakat Makassar mengenal atau diperkenalkan pada agama Islam. Sinkretisasi yang dimaksud di sini menyangkut dua sistem prinsip yang berbeda, yakni Islam dan pra-Islam. Secara sederhana yang dimaksud dengan prinsip atau pandangan hidup orang Makassar pra-Islam di sini adalah keseluruhan perangkat nilai, pandangan hidup, aturan, dan pengetahuan yang dianut oleh orang Makassar sebelum diterimanya prinsip-prinsip ajaran Islam sebagai pedoman bagi kehidupan sebagian besar orang Makassar, atau diterimanya ajaran-ajaran Islam sebagai perangkat pandangan hidup.
\end{abstract}

Kata Kunci: singkretis, sinrilik, budaya

\begin{abstract}
The research is qualitative that applies syncretism on Sinrilik Datu Museng and Maipa Deapati (culturalcomparative study of Gowa regency). Then, the assimilation and combination of native and non-native aspects emerge a new culture called syncretization; syncretic phenomenon is mainly on belief system that undertakes the change. The change happens after Makassarese people know and introduce to Islamic religion. Syncretism meants is two different principles, Islam and pre-Islam. Simply, principle or Makassarese preIslam view of life is all values, rules, and knowledge known by Makassarese people before Islamic principles are accepted as life guidance of some Makassarese people or as view of life.
\end{abstract}

Keywords: singkretis, sinrilik, cultur

\section{PENDAHULUAN}

I ndonesia adalah negara kepulauan yang memiliki bermacam-macam suku, agama, budaya, bahasa, dan ras. Keanekaragaman itu merupakan kekayaan nasional yang membedakan Indonesia dengan bangsa lainnya di dunia. Keanekaragaman itu pulalah yang merupakan ciri khas bangsa Indonesia di dunia.

Salah satu kekayaan bangsa Indonesia seperti yang dipaparkan sebelummnya adalah adanya keanekaragaman budaya. Pada dasarnya setiap daerah atau wilayah di Indonesia memiliki kebudayaan masing-masing yang terwujud dalam kebudayaan nasional bangsa Indonesia. Kebudayaan daerah itu yang memperkaya kebudayaan bangsa.

Oleh karena itu, usaha penggalian dan inventarisasi serta pengembangan budaya daerah mempunyai arti yang sangat penting, bukan saja bagi kebudayaan daerah itu sendiri melainkan juga untuk kepentingan kebudayaan nasional. Jadi apabila kita kaitkan dengan pendapat yang menyatakan bahwa 
sastra adalah bagian dari kebudayaan (Robson, 1987:6), maka hal itu dapat diterima. Jadi, sastra daerah adalah bagian dari kebudayaan daerah yang mempunyai arti yang sangat penting bagi sastra Indonesia yang juga merupakan bagian dari kebudayaan nasional Indonesia.

Salah satu warisan yang dimiliki bangsa Indonesia adalah kebudayaan daerah. Usaha penggalian sastra daerah itu tentu tidak tergolong ke dalam menonjolkan rasa atau sifat kedaerahan, tapi hanya bertujuan untuk mencari dasar-dasar yang dapat disumbangkan bagi pengembangan sastra Indonesia (Parawansa dkk,1992:1).

Sastra daerah merupakan salah satu kekayaan budaya bangsa yang mengandung nilai penting, karena melalui sastra daerah maka budaya daerah yang beraneka ragam dapat dilestarikan. Keberadaan kebudayaan nasional yang bercorak Bhineka Tunggal Ika tidak munkin akan terwujud tanpa landasan bahasa dan sastra daerah sebagai wahana penyanggah kebudayaan nasional.

Pengkajian sastra Makassar termasuk masih sangat jarang dilakukan, terutama sebagai objek penelitian. Selama ini, perhatian para ahli masih terbatas pada usaha penginventarisasian dan pendokumentasian dalam bentuk transliterasi, transkripsi, dan terjemahan seperti yang dilakukan Matthes (1985), Parawansa, dkk. (1992), Hakim (1992 dan 1995), dan Manyambeang (1998). Sedangkan kajian dalam bentuk makalah dilakukan Nasruddin (1998). Minimnya perhatian dan kurangnya penelitian mengenai sastra Makassar itulah sebagai dasar pertimbangan bagi peneliti untuk menjadikan sastra Makassar, dalam hal ini sinrilik, sebagai objek kajian.

Sastra Makassar sarat dengan nilai kemanusiaan dan kehidupan karena sastra Makassar juga memiliki sifat-sifat keuniversalan sebagaimana yang dimiliki sastra, pendapat tersebut telah lama dikemuka-kan oleh Horatius (dalam Teeuw, 1988:183) dalam Ars Poetica-nya bahwa fungsi sastra ada dua, yaitu utile (bermanfaat) dan dulce (memberi kenikmatan). Mangunwijaya (2003:17) berpendapat bahwa karya sastra dianggap sesuatu yang tinggi nilainya. Sesuatu yang mempunyai nilai dan sangat berharga. Lebih lanjut, Mangunwijaya (2003:19) menambahkan bahwa sastra mempunyai peran tersendiri dalam kehidupan masyarakat. Sastra berperan dalam membentuk insan yang budiman, yang mengasah nurani, dan yang membuat manusia menjadi lebih manusiawi. Sastra memberi keseimbangan dalam hidup manusia dan mengisi ruang-ruang dalam pribadi yang tidak mungkin disentuh melalui media lain. Sastra lebih tertuju pada batin manusia dan membuat pencerahan.

Pendek kata, sastra mempelajari masalah manusia dan kemanusiaan. Dalam karya sastra, masalah manusia dengan segala kompleksitasnya digarap secara estetis dan dramatis. Sehubungan dengan ruang lingkup penggarapan masalah dalam karya sastra, Unger (dalam Wellek dan Austin Warren, 1999:141-142) mengklasifikasi lima permasalahan yang selalu digarap pengarang. Pertama, masalah nasib, seperti hubungan antara kebebasan dan keterpaksaan atau semangat manusia dan alam. Kedua, masalah keagamaan, seperti interpretasi tentang Tuhan, sikap terhadap dosa dan kematian. Ketiga, masalah alam, seperti perasaan terhadap alam, mitos, dan alam gaib. Keempat, masalah konsep manusia, seperti hubungan manusia dengan kematian, konsep mengenai cinta. Kelima, masalah masyarakat, keluarga, dan negara.

Contoh beberapa kutipan yang dikemukakan tersebut membuktikan bahwa teks cerita sinrilik mengandung nilai kemanusiaan. Untuk lebih mengungkapkan secara mendalam dan mendetail tentang nilai kemanusiaan dalam sinrilik, maka perlu diadakan penelitian yang intensif dan komprehensif. Dengan demikian, ada beberapa alasan yang mendorong dan sekaligus menjadi bahan pertimbagan bagi peneliti untuk meneliti topik ini, yaitu: (a) sinrilik sebagai salah satu warisan budaya masa silam perlu digali, dijaga, dipelihara, dan dilestarikan dengan cara, antara lain, diteliti dan dikaji; (b) penelitian mengenai sinrilik sastra lisan Makassar masih terbilang sangat minim dilakukan dan pada umumnya penelitian yang dilakukan masih bersifat dokumentasi; dan (c) sinrilik diduga mengandung nilai kemanusiaan sehingga dapat dijadikan sebagai wahana dalam pendidikan dan pembinaan nilai budaya masyarakat etnis Makassar pada khususnya dan budaya bangsa Indonesia pada umumnya.

Hubungan kemanusiaan yang dimaksud dalam uraian di atas adalah memantapkan posisi jati diri antara manusia dengan manusia, hubungan manusia dengan tuhannya dalam hal ini adalah kepercyaan yang dianutnya. Dalam masyarakat Makassar yang tertuang dalam cerita sinrilik masih ada perpaduan antara kebudayaan Hindu dan Islam yang dapat bercampur baur menjadi satu. Oleh karena itu peneliti sangat tertarik untuk melihat secara detail wujudnya dalam teks sinrilik dan membandingkannya dengan perilaku kehidupan masyarakat modern saat ini khususnya di Kabupaten Gowa. 


\section{Kajian Teori \\ Pengertian Sinrilik}

Sinrilik tergolong prosa berirama dalam sastra lisan Makassar. Sinrilik merupakan cerita yang dibawakan secara puitis dan berirama serta dimainkan oleh seorang yang ahli atau juru cerita yang dinamakan pasinrilik. Dalam penyampaian sinrilik, pasinrilik menggunakan alat musik kesokkesok sebagai pengiringnya. Sinrilik merupakan tradisi pembacaan lisan dalam khasanah kebudayaan etnis masyarakat Makassar yang hingga sekarang ini masih tetap ada, namun perkembangan dianggap sangat lamban.

Menurut Mangemba (dalam Bahrum dan Indri Lewa, 1996:21) Pada mulanya sinrilik dikenal dengan istilah kesok-kesok atau kerek-kerek gallang. Kesok-kesok adalah sejenis rebab dengan dua dawai yang digesek. Dawai itu biasanya menggunakan dawai biola, tetapi adakalanya menggunakan kawat (kabel) telepon. Adapun alat yang digunakan untuk menggeseknya terbuat dari bulu ekor kuda.

Pendapat mengenai sinrilik dikemukakan beberapa ahli. Matthes (1985:777) dalam bukunya Makassarsch Nederlandsch Woodenboek menjelaskan pengertian sinrilik, yaitu "sinrilik bepa sinrilika, sort van gedicht be vergelijken eat het mal. N. B. Wanner zulk een sinrilik elnvouding gelezen, met gezongen wort, noemtmen die kakakung" (sinrilik dalam bentuk tertentu sinrilika, sejenis puisi, dapat disamakan dengan syair dalam bahasa Melayu. N.B apabila sinrilik hanya dibacakan saja dan tidak dinyanyikan, maka dinamakan lalakung).

Parawansa, dkk. (1992:1-20) mengartikan sinrilik sebagai cerita yang tersusun secara puitis yang diceritakan, mungkin lebih tepat disebut dinyanyikan/dilagukan oleh seorang ahlinya serta lazimnya diiringi dengan alat musik kesok-kesok sejenis rebab. Sinrilik itu sendiri adalah sebuah cerita yang tersusun secara puitis atau lyrisch-prosa, diceritakan (dinyanyikan) oleh seorang ahlinya (dalang dalam bahasa Jawa) serta diiringi oleh sebuah alat yang digesek, yang dinamai kesok-kesok (rebab).

Cense (dalam Arief dan Zainuddin Hakim, 1993:1) menyatakan bahwa sinrilik ialah syair yang singkat dan liris atau panjang dan epos. Berdasarkan pendapat cense tersebut, Arief dan Zainuddin Hakim (1993: 1) menegaskan bahwa sinrilik adalah karya sastra yang berbentuk prosa lirik atau prosa berirama dan dapat dilagukan baik dengan alat musik maupun tanpa alat musik.
Basang dan Salmah Djirong (1997:71) mengemukakan definsi sinrilik sebagai sejenis bahasa berirama yang melukiskan suka duka dalam menghadapi hidup dan tantangan hidup serta menggambarkan perjuangan dan kepahlawanan. Oleh karena itu, kalau dinyanyikan ada yang cocok diiringi kesok-kesok (rebab) dan ada pula yang tidak cocok diiringi kesok-kesok (rebab).

Berdasarkan berbagai pendapat mengenai pengertian sinrilik ter-sebut, dapat disimpulkan bahwa sinrilik adalah sebuah cerita yang ter-susun secara puitis, liris, dan berirama yang diceritakan dan dinyanyi-kan seorang ahli (pasinrilik). Dalam membawakan sinrilik, seorang pasinrilik pada umumnya menggunakan alat musik kesok-kesok (rebab) yang digeseknya sendiri. Isi cerita sinrilik beragam, mulai dari pelukisan suka duka dalam menghadapi tantangan kehidupan, percintaan, kesetiaan dan kejujuran, perjuangan melawan penjajah, sampai pada kepahlawanan seorang tokoh.

Sinrilik sangat digemari dan masih hidup di tengah-tengah masyarakat yang berbahasa Makassar di Sulawesi Selatan. Menurut Arief dan Zainuddin Hakim (1993:2), wilayah pemakaian bahasa Makassar berdasarkan pembagian administratif di Sulawesi Selatan, meliputi (1) sebagian pesisir Kabupaten Pinrang, (2) bagian barat Kabupaten Pangkajene Kepulauan, (3) bagian Barat dan Selatan Kabupaten Maros, (4) Kotamadya Ujung Pandang (sekarang Kota Makassar), (5) Kabupaten Gowa, (6) Kabupaten Jeneponto, (7) sebagian besar Kabupaten Ban-taeng, (8) sebagian besar Kabupaten Bulukumba, (9) Kabupaten Selayar, (10) bagian Barat dan Tenggara Kabupaten Sinjai, dan (11) perbatasan bagian Selatan Kabupaten Bone.

Pada awalnya, sinrilik diceritakan secara lisan. Namun, dewasa ini sinrilik telah pula didokumentasikan secara tertulis. Oleh karena itu, teks cerita sinrilik sudah dapat diperoleh dengan mudah, tidak seperti ketika masih dalam bentuk penceritaan secara lisan. Dari penelitian Parawansa, dkk. (1992) telah didokumentasikan beberapa sinrilik, di antaranya empat yang dianggap sebagai sinrilik yang paling populer dan merupakan puncak sinrilik di Sulawesi Selatan, yaitu Sinrilik Kappalak Tallum Batua (SKTB), Sinrilik Datumuseng (SD), Sinrilik I Makdik Daeng Rimakka (SMDR), dan Sinrilik I Manakkuk (SM).

\section{Sinkretisme}

Beberapa manusia dalam menghayati dan mengamalkan ajaran agamanya memberikan penekan-penekanan khusus pada aspek-aspek 
tertentu dari agamnya itu. Sebagian ada yang menekankan pada penghayatan mistik, ada yang menekankan pada penalaran logika, penekanan pada aspek pengamalan ritual, dan ada juga yang menekankan pada aspek pelayanan (amal shalih). Untuk lebih jelasnya akan diuraikan sebagaimana berikut ini:

Cara mistik. Dalam menghayati dan mengamalkan ajaran agamanya, sebagian manusia cenderung lebih menekankan pada pendekatan mistikal daripada pendekatan yang lain. Cara mistik seperti ini dilakukan oleh para sufi (pengikut tarekat) dan pengikut kebatinan (kejawen). Adapun mistik itu sendiri adalah suatu pengamalan yang dilakukan oleh pengikut agama tertentu yang lebih menekankan pada aspek pengamalan batiniah (esoterisme) dari ajaran agama, dan mengabaikan aspek pengamalan formal, struktural dan lahiriyah (eksoterisme). Pada setiap pengikut agama apapun agamanya baik agama besar maupun agama lokal, selalu memiliki kelompok pengikut yang memberi perhatian besar pada cara beragama mistik ini. Di kalangan pengikut agama Islam dikenal dengan sufisme, dikalangan umat Katolik dikenal dengan hidup kebiaraan, begitu pula dikalangan Hindu maupun Buddhisme. Beragama dengan cara mistik sangat digemari oleh masyarakat berkebudayaan tertentu, yang secara kultur dominan, mereka menekankan pada hal-hal mistiktikal tersebut, seperti sebagian masyarakat yang berkebudayaan jawa. Kebudayaan jawa adalah tipe kebudayaan yang menekankan pada hidup kerohanian bersifat esoteris dan menjunjung tinggi harmonitas hidup sehingga kadangkala menyebabkan terjadinya sinkritisme.

Cara penalaran, di samping penghayatan dan pengamalan agama cara mistik, ada pula cara penalaran, yaitu cara beragama dengan menekankan pada aspek rasionalitas dari ajaran agama. Bagi penganut aliran ini, bagaimana agama itu harus dapat menjawab masalah yang dihadapi penganutnya dengan jawaban yang masuk akal. Beragama tidak selamanya harus menerima begitu saja apa yang didoktrinkan oleh pimpinan agama, mereka menyenangi interpretasi yang bebas dalam menafsirkan teks dari kitab suci atau buku-buku agama lainnya. Dari tradisi Islam umpamanya, ada kelompok yang disebut mutakalimin atau para ahli ilmu kalam, yang banyak membicarakan teologi Islam dengan memakai dalil tekstual (naqli) dan dalil rasional (aqli).
Cara amal shaleh. Cara beragama yang ketiga ini lebih menekankan pengahayatan dan pengamalan agama pada aspek peribadatan, baik ritual formal maupun aspek pelayanan sosial keagamaan. Menurut kelompok ini, yang terpenting dalam beragama adalah melaksanakan amal shaleh, karena indikator seseorang beragama atau tidak ialah dalam pelaksanaan segala amalan lahir dari agama itu sendiri. Tuhan memasukkan seorang manusia ke dalam surga adalah karena amal shalih orang tersebut yang dilakukan ketika ia masih hidup. Tidak ada artinya pengakuan dan iman dalam hati kalau tidak dinyatakan dalam amal perbuatan fisik dan perwujudan materi. Dalam agama Islam, kelompok ini lebih banyak mengikuti ajaran fiqih dan hukum-hukum agama mengenai tata cara amal shalih daripada amal yang lainnya.

Cara sinkretisme. Salah satu sifat dari masyarakat Jawa adalah bahwa mereka religius dan bertuhan. Sebelum agama-agama besar datang ke Indonesia, khususnya Jawa, mereka sudah mempunyai kepercayaan adanya Tuhan yang melindungi dan mengayomi mereka. Keberagamaan ini semakin berkualitas dengan masuknya agamaagama besar seperti Hindu, Buddha, Islam, Katolik, dan Protestan ke Jawa. Namun, dengan pengamatan selintas dapat diketahui bahwa dalam keberagamaan rata-rata masyarakat Jawa adalah nominalis, dalam arti bahwa mereka tidak bersungguh-sungguh dalam melaksanakan ajaran-ajaran agamanya.

Ada di antara mereka yang benar-benar serius dalam menjalankan ajaran-ajaran agamanya. Ada juga yang berusaha untuk serius tetapi karena hambatan-hambatan khusus, seperti ewuh dengan lingkungan yang tidak mendukung, takut dikatakan sok suci semuci dan sebagainya, membuat mereka kikuk dalam mengekspresikan keagamaannya secara utuh. Dalam hal ini bisa saja mereka mengaku sebagai orang muslim, yang untuk itu mereka bersedia dikhitan, membaca syahadat ketika akan melaksanakan akad nikah, melakukan shalat Idul Fitri, membaca surat Yasin dan tahlil ketika diundang selamatan oleh tetangga dan kerabatnya, menghadiri pengajian pada hari-hari besar Islam, memberikan sumbangan untuk pembangunan masjid dan sebagainya.

Namun untuk benar-benar serius dan sungguh-sungguh dalam menjalankan syariat Islam, seperti salat lima waktu dengan berjamaah, puasa sebulan penuh dalam bulan Ramadhan, membayar zakat mal (zakat yang berkaitan dengan penghasilan yang mereka terima dan harta yang 
mereka miliki), dan amala-amalan agama lainnya yang relatif sulit dilaksanakan serta membutuhkan keseriusan, mereka enggan mengerjakannya. Karena kurangnya keseriusan dalam memahami dan mengamalkan agamanya, berakibat kepada beberapa hal, yang antara lain mudahnya mereka tergiur dalam mengadopsi kepercayaan, ritual, dan tradisi dari agama lain yang termasuk tradisi asli pra Hindu-Buddha yang dianggap sesuai dengan alur pemikiran mereka. Oleh karena itu, meskipun mengaku sebagai seorang muslim, mereka juga meletakkan kembang setaman dan sesaji lainnya di tempat-tempat khusus pada hari-hari tertentu, mengadakan ruwatan untuk anak-anaknya yang perlu diruwat, melakukan laku khusus pada malam satu Suro, dan mengeramatkan keris serta bendabenda pusaka lainnya. Selain itu ketika anaknya mau menghadapi ujian, ia melakukan tirakat berupa puasa mutih, ziarah dan nyepi di makam leluhurnya yang dulu dikenal mempunyai kekuatan linuwih serta laku-laku tirakat lainnya. Hal ini mereka lakukan dalam rangka mencari kedamaian dan ketenangan dalam menghadapi ketegangan akibat munculnya berbagai problematika kehidupan yang menumpuk. Dengan demikian, secara sadar atau tidak, mereka telah melakukan sinkretisasi antara ajaran Islam dengan ajaran-ajaran dari luar Islam (Buddha, Hindu, dan Kepercayaan asli). Sebagai contoh dari sinkretisme antara dua agama yang berbeda adalah penggabungan antara agama Islam dan Hindu di India, seperti yang dilakukan oleh Guru Nanak (1469-1538).

Ketika melihat adanya konflik yang berkepanjangan antara pemeluk agama Islam dan agama Hindu, Guru Nanak berinisiatif untuk menggabungkan ajaran-ajaran kedua agama besar tersebut, dengan mengambil unsur-unsur yang dianggap baik dari keduanya, sebagai ajaran agama baru yang dibentuknya. Gabungan kedua agama ini disebut agama Sikh, dengan ajaran-ajaran yakni: 1) Percaya satu Tuhan (Hari), 2) Melarang pemujaan arca-arca keagamaan, 3) Percaya reinkarnasi dan hukum karma, 4) Membuang upacara-upacara keagamaan, 5) Mengajarkan persamaan hak dan martabat laki-laki dan wanita, 6) Menghindari kegiatan keduniawian, 7) Menjauhi minuman keras dan rokok, dan 8) Menjalankan hidup damai dan benar.

Dari ajaran-ajaran di atas terlihat bahwa agama Sikh sangat dipengaruhi oleh ajaran-ajaran Islam (percaya kepada Tuhan yang satu dan melarang pemujaan terhadap arca), dan ajaran-ajaran Hindu (percaya kepada reinkarnasi dan hukum karma).

\section{Metode Penelitian}

Metode yang digunakan dalam penelitian ini adalah metode deskriptif kualitatif artinya data yang dianalisis dan hasil analisisnya berbentuk deskripsi dan tidak berupa angka-angka. Pengkajian ini bertujuan mengungkap berbagai informasi kualitatif dengan pendeskripsian yang teliti dan mengambarkan secara cermat sifat-sifat suatu hal (individu/ kelompok).

Penelitian ini tidak terbatas pada pengumpulan data saja, melainkan meliputi analisis dan interpretasi. Hasil penelitian dalam penelitian ini berupa kutipan-kutipan data yang berisi nilai edukatif dalam karya sastra yang menggunakan pendekatan psikologi sastra.

Teknik yang digunakan dalam penelitian ini adalah jenis teknik kualitatif. Analisis kualitatif dapat digolongkan ke dalam metode deskriptif yang penerapannya bersifat menuturkan, memaparkan, memberikan, menganalisis, dan menafsirkan.

\section{PEMBAHASAN \\ Sinkretisasi Sinrilik Datu Museng dan Maipa Deapati}

Sinkretisasi adalah penyesuaian atau adaptasi, yang diartikan sebagai sebuah proses mengkombinasi sifat-sifat yang asli dengan yang asing. Proses penggabungan dan pengkombinasian unsur-unsur asli dengan unsur-unsur asing ini kemudian memunculkan sebuah pola budaya baru yang dikatakan sinkretis. Fenomena sinkretisasi diarahkan terutama pada sinkretisasi yang terjadi pada sistem kepercayaan, yang memang mengalami perubahan. Perubahan dimaksud yang terjadi adalah setelah masyarakat Makassar mengenal atau diperkenalkan pada agama Islam.

Memang benar adanya bahwa pandangan tentang budaya Makassar yang Islam tidak sepenuhnya Makassar juga sekaligus tidak sepenuhnya Islam. Unsur-unsur lokal, pra-Islam juga cukup dominan menginterferensi dalam kehidupan keagamaan masyarakat Makassar. Hal inilah yang menyebabkan ciri asli ajaran agama Islam dan pra-Islam agak susah dikenali. Meskipun, Islam di Makassar sebenarnya merupakan Islam yang telah menyatukan dalam dirinya unsurunsur lokal pra-Islam, atau Islam yang sinkretis. Perbedaannya terletak pada derajat atau tingkat kedalaman "penyerapan" Islam yang terjadi dalam masyarakat.

Sinkretisasi yang dimaksud di sini menyangkut dua sistem prinsip yang berbeda, yakni Islam dan pra-Islam. Secara sederhana yang dimaksud dengan 
prinsip atau pandangan hidup orang Makassar praIslam di sini adalah keseluruhan perangkat nilai, pandangan hidup, aturan, dan pengetahuan yang dianut oleh orang Makassar sebelum diterimanya prinsip-prinsip ajaran Islam sebagai pedoman bagi kehidupan sebagian besar orang Makassar, atau diterimanya ajaran-ajaran Islam sebagai perangkat pandangan hidup.

Oleh karena sinkretisasi ini selalu mengenai prinsip-prinsip, ajaran-ajaran atau pemikiranpemikiran serta proses penyatuan yang terdapat di dalamnya, fokus pembahasan kita kali ini berada pada tingkat penafsiran atau simbolisasi prinsipprinsip atau ajaran yang ada karena sebenarnya proses sinkretisme ini terjadi pada tingkat tersebut.

Berikut kutipan-kutipan dalam sinrilik yang merupakan bukti adanya sinkretisasi ajaran agama pra-Islam dan Islam.

Datu Museng akkana siagang sakrak tatak: "iyaji bawang mange ri Makkah siagang Madina, tok? Iyaji bawang angngarungi tamparang siagang jeknek bombing, angnginroi parang tattarak akparang kassi? Teaki bata-batai, manna mange ri tamparang pepeka kulampai tikring anggappai mutiara tallasakku

Terjemahan:

Dengan suara pasti Datu Museng berkata: "Hanya ke Mekkah dan Madinah, kek?" Cuma mengarungi laut berombakkan air, menjelajah sahara berpadangkan pasir? Tak usah kuatir, ke laut api sekalipun aku akan pergi, demi mendapatkan mutiara hidupku.

Salah satu latar yang juga digambarkan dalam sinrilik ini adalah latar tempat Mekkah dan Madinah. Kedua tempat tersebut merupakan tempat ziarah orang-orang muslim. Jadi, dapat diinterpretasikan bahwa tokoh utama dalam sinrilik ini menganut agama Islam.

Selanjutnya, kutipan berikut mengimplikasi adanya sistem kasta.

Singkammai bulaeng I Manggalasa taena tauji. Attangngang Datu Museng tena na creak bawang, lekbak akcampuruki perak

Terjemahan:

I Manggalasa ibarat emas tiada teruji baginya. Sedangkan Datu Museng sudah bercampur perak, darahnya tidak tulen lagi.
Salah satu alasan kedatangan Islam di Indonesia disambut hangat adalah karena tidak adanya sistem kasta seperti agama pra-Islam. Meskipun dalam sistem perkawinan, Islam juga mensyaratkan adanya pertimbangan nasab atau keturunan namun ini bukan hal yang diutamakan. Oleh karena itu, sistem kasta yang dianut tokohtokoh dalam sinrilik ini merupakan sistem kasta yang sangat lekat dengan sistem kasta pra-Islam di mana seseorang diukur dari keaslian darah turunannya.

Singkamma tong anne bangngia,
doangangangna Datu Museng akbutti.
Pangnguasa anging, dewa guruh siagang kilak
appada annosok kale siagang appakasimbung,
anrumbang pokok-pokok

Terjemahan:

Demikian pula malam ini pinta sang Datu Museng terkabul lagi. Penguasa angin, dewa guruh dan kilat serentak menjelmakan diri dan mengamuk menumbangkan pohonpohon.

Pada kutipan terdahulu, berdasarkan latar tempat yang terlibat dalam cerita, Datu Museng terindikasi beragama Islam karena ketika harus berguru, sang kakek memintanya ke Mekkah dan Madinah. Namun, kutipan di atas mengimplikasi adanya perbauran ajaran agama Islam dan praIslam. Islam hanya mengakui adanya satu Tuhan, satu penguasa langit dan bumi, dan satu penguasa seluruh jagat raya. Ketika menginginkan sesuatu dari-Nya, mintalah langsung pada-Nya tanpa perantara karena itu janji-Nya, berdoalah pada-Ku dan aku akan mengabulkannya untukmu. Namun, tokoh dalam sinrilik ini ketika meminta sesuatu menyebut penguasa angin dan dewa guruh. Dua kata yang tidak pernah digunakan untuk mereferensi Tuhan yang dipercaya pemeluk agama Islam. Dua kata ini malah sangat lekat dengan Tuhan yang dianggap Tuhan oleh ajaran pra-Islam.

Akkurungi ia ilalang bilikna siagang ratu nisombaya ati nampa nariwami kammakamma anne, lekbak narakakmi kammakamma anne. Kamma-kamma anne tenamo nakalannak-lannassang ampakarumbu umbu, mingka aknassami narakak tekngerek tuningaina. 
Terjemahan:

Ia berkurung dalam bilik bersama ratu pujaan hatinya yang kini sudah di pangkuan, sudah dalam pelukannya kini. Ia tidak lagi menghayalkan menggantam asap sekarang, tapi sudah nyata memeluk kekasih belahan jiwanya.

Tak terdefinisi dalam alur sebelumnya bahwa Datu Museng sebagai tokoh utama dan kekasihnya melakukan pernikahan. Namun, kutipan di atas menyatakan mereka sudah berada dalam satu kamar, sang kekasih duduk di pangkuan bahkan berada dalam pelukan. Secara normatif bahkan dalam adat ketimuran, perbuatan mereka sangat tidak lazim. Islam mengatur ketat masalah yang terkait dengan hal ini. Ini dikarenakan melawan hawa nafsu merupakan perjuangan terberat yang dialami manusia bahkan sanksi bagi yang melanggar aturan ini adalam rajam. Namun, asumsi terkuat penyebab terjadinya sinkretisasi ini adalah karena ajaran agama yang terdahulu memang menguratakar dalam pola pikir dan Islam pun datang dengan perlahan-lahan, tidak dengan sekaligus mengubah kebiasaan-kebiasaan mereka.

Ingka tenapa napasuluki badikna Datu Museng battu ri tampakna, akkanai Maipa Deapati: "Daeng, papalaloi andikta angngalle jeknek sambayang...!" ambangungmi namange ri boko angngalle jeknek sambayang

Terjemahan:

Tapi sebelum keris pusaka tercabut dari sarungnya, Maipa Deapati berkata: "Kanda, izinkan adinda mengambil air sembahyang...!" ia kemudian bangun lalu menuju ruang belakang mengambil air sembahyang.

Kutipan di atas merupakan gambaran salah satu rentetan peristiwa sebelum Datu Museng dan Maipa Deapati memutuskan untuk bunuh diri. Dalam ajaran Islam, berwudhu atau mengambil air sembahyang memang gunanya untuk menyucikan diri dari hadas kecil dan wajib dilakukan sebelum melakukan ritual shalat. Namun, dilakukan sebelum bunuh diri merupakan ajaran yang tidak pernah tersurat dan tersirat dalam dua pedoman utama umat Islam. Lebih lanjut lagi, ketidakmurnian ajaran Islam yang dipahami nampak dalam kutipan berikut.
Akkanai pole Datu Museng:" aklampamako andik, tayangmi daengnu ri butta bakleang, ri surugana Firdaus. Tayangma riwattu lohorok. Punna daengnu tenapa nabattu, tayanga ri wattu asarak. Punna tenapa nakubattu tayanga ri wattu mangngaribi punna lakbiringmi tallang mata alloa ri tampakna. Anjo wattu, attantumi kabattuanna daengnu ammuntuli.

Terjemahan:

Datu Museng kemudain berkata lagi: Pergilah adinda, tunggulah kanda di tanah seberang di alam indah permai di surga Firdausi. Tunggu aku di waktu lohor. Jika kanda belum datang, nantikan di waktu asar. Apabila aku belum juga tiba, nantikanlah pada waktu magrib, ketika matahari sedang bersiap-siap masuk ke peraduannya.

Simbol-simbol yang digunakan di atas, referensinya merujuk ke ajaran Islam, seperti zuhur, asar, magrib, dan surga Firdausi. zuhur, asar, dan magrib merupakan tiga dari lima waktu di mana setiap muslim wajib menunaikan kewajibannya, salah satu dari lima tiang agamanya yaitu salat. Sedangkan surga Firdausi adalah satu dari tujuh pintu surga yang dijanjikan bagi umat Islam. Namun, kematian adalah rahasia Sang Pemilik Jiwa. Tidak seorang pun tahu kapan detak jantungnya akan berhenti dan dalam kehidupan setelah kematian akan berada di mana, surgakah atau neraka. Lantas, mengapa Datu Museng meminta Maipa Deapati menanti kedatangannya di surga. Tidakkah setelah perjalannya ke Mekah dan Madinah mencari ilmu membuatnya tahu bahwa bunuh diri bukanlah hal yang patut dilakukan bagi seorang muslim meskipun itu dilakukan dengan mengucap nama Tuhan seperti yang termaktub dalam kutipan di bawah.

Nasabbukna arengna karaeng allah Ta'ala, natongkokna todong matanna Datu Museng akgiokna todong badikna angsamballei kallonna bainenna

Terjemahan:

Dengan mengucap nama Tuhan, sambil mata dipejamkan, Datu Museng menggerakkan keris terhunus itu menyembelih ke leher istrinya. 
Proses sinkretis ajaran Islam dan pra-Islam yang sampai saat ini juga masih dipegang teguh oleh beberapa orang adalah ajimat seperti yang dimiliki oleh Datu Museng:

Pangngaina na janjina mange ri tunangaina ri bakleang _ri alam baka_ Datu Museng annappuk: aklappassang jima panjaga batang kalenna battu ri kalenna. Nabuntuli Karaeng Galesong nampa napassareang anjo jimaka mange ri iya.

Terjemahan:

Didorong keyakinan yang kuat, lebih cinta pada janji dan sumpah terhadap kekasih di seberang di alam baka ia segera mengambil keputusan terakhir: menanggalkan ajimat penjaga diri dari tubuh. Kemudian dicapainya Karaeng Galesong dan menyerahkan ajimat itu padanya.

Jimat merupakan salah satu yang sangat dilarang dalam ajaran Islam karena ini berarti menjadikan yang lain selain Tuhan sebagai tempat bersandar. Padahal dalam Islam Tuhan merupakan salah satu tempat untuk meminta dan bersandar. Menjadikan yang lain sebagai tempat bersandar merupakan dosa besar, hal ini idealnya tercermin dalam sikap dan pandangan hidup Datu Museng karena dia mendapatkan ilmu mengenai Islam di tempat asalnya.

Islam adalah agama yang menyeluruh, semua lini kehidupan telah memiliki pedoman sendirisendiri. Bahkan dengan tegas Islam mengajarkan agar tidak ada percampuran antara yang hak dan yang batil. Namun, ketika tradisi dan ajaranajaran pra-Islam masih memengaruhi sikap dan pandangan hidup mereka dalam kehidupan seharihari seperti yang tercermin dalam sinrilik Datu Museng merupakan hal yang memang lumrah terjadi ketika sinkretisasi yang terjadi tidak secara keseluruhan.

Faktor internal ialah faktor yang berkaitan dengan hal yang ada di dalam pribadi I Datu Museng, yaitu faktor keinginan mempersunting putri Maipa Deapati.

I Baso Mallarangang atau yang lebih dikenal dengan I Datu Museng adalah seorang pemuda berdarah Makassar. Sejak kanak-kanak ia sudah berada di negeriSumbawa. Ia diasingkan ke negeri itu oleh kakeknya (Adearangan) untuk menyelamatkan jiwanya dari amukan para perampok di Makassar. Karena itu, I Datu Museng tumbuh menjadi pemuda di Sumbawa dibawa asuhan kakek Adearangan.

Ketika agama Islam baru masuk di tanah Sumbawa, para orang tua mengharuskan putraputrinya untuk memperdalam ilmu agama. Karena itu, para orang tua dari berbagai golongan masyarakat kemudian beramai-ramai mendaftarkan diri sebagai santri dan santriwati di perguruan milik Kadhi Mampawa, tak terkecuali I Datu Museng dan putri Sultan Sumbawa, Maipa Deapati. Pertama kali melihat Maipa Deapati, I Datu Museng langsung terpikat. Keterpikatan I Datu Museng kepada putri tunggal Makgauka itu bukan karena putri pejabat nomor satu di Sumbawa, bukan pula karena keturunan bangsawan tinggi, melainkan karena kecantikannya laksana bidadari. Maipa Deapati merupakan kembang semerbak dan harumnya tak ada duanya. Maipa Deapati merupakan bintang kejora di tengah malam dan suluh dalam gelap. Demikian penilaian I Datu Museng terhadap putri Maipa. Begitu dalam kekaguman I Datu Museng melihat putri itu. Jika tak melihat anak dara itu walau dalam sekejap, hati I Datu Museng amat gelisah. Sebaliknya, jika bertemu, apalagi bertatap pandang, hati I Datu Museng menjadi girang alang-kepalang. Muncullah keinginan dalam hati I Datu Museng untuk mempersunting putri tunggal Makgauka itu dan berjanji untuk melakukan apa saja asal keinginannya terpenuhi.

Berpikir keraslah I Datu Museng mencari cara terbaik untuk mengakrabkan dan mempertautkan hatinya dengan putri Maipa. Berbagai cara pun muncul dalam pikirannya. Akan tetapi, yang dipilih I Datu Museng adalah sebuah permainan tradisional yang saat itu digandrungi oleh muda-mudi di Sumbawa. Bentuk permainan tradisional itu disebut akgalacang (permainan yang menggunakan sebilah kayu berlubang yang diisi dengan batu-batuan yang dimainkan dua orang yang saling berhadapan). Cara itu pun diujicobakan dan hasilnya cukup memuaskan. Putri Maipa amat menggemari permainan tersebut. Kedua insan yang berlainan jenis itu tak pernah melewatkan permainan tersebut, baik sebelum dan sesudah pengajian. Setiap kali mereka bermain I Datu Museng selalu membuat kesalahan yang disengaja agar permainan itu tak cepat berakhir. Kesempatan seperti inilah yang digunakan I Datu Museng untuk bersilat mata sambil menyelinginya dengan cubit-cubitan. Karena kerap kali bertemu, akhirnya tumbuh benih-benih cinta di antara mereka. Kebahagiaan I Datu Museng pun tak terkirakan karena cintanya bersambut. 
Pada saat cinta mulai bersemi, I Datu Museng membuat masalah, yaitu mengambil cincin milik Maipa ketika tiba-tiba keluar dari jari manisnya. Hal itu dilakukan dengan maksud lebih mempererat cinta mereka. Namun, maksud itu justru mendatangkan malapetaka baginya. Kadhi Mampawa (guru mereka) yang melihat peristiwa itu menganggap hal itu merupakan suatu pelanggaran adat, karena melecehkan martabat seorang wanita bangsawan di depan khalayak. Sebagai ganjarannya, I Datu Museng diusir dari tempat pengajiannya dan diminta mencari guru lain. Saat itu, hati I Datu Museng menjadi gemas bercampur sedih. Ia sadar bahwa dengan pengusiran itu berarti dirinya tak dapat lagi bertemu dan bersilat mata dengan pujaan hatinya.

Segeralah I Datu Museng meninggalkan tempat pengajian itu menuju rumahnya untuk mengadukan nasib yang baru dialaminya kepada kakeknya, Adearangan. Harapannya adalah agar sang kakek dapat membantunya mengatasi derita batinnya. Begitu tercengang sang kakek tatkala melihat cucu kesayangannya muncul di rumah dalam keadaan sedih tak terkirakan. Karena penasaran, apa gerangan yang telah terjadi, Adearangan bertanya kepada sang cucu. Beberapa kali pertanyaan keluar dari mulut Adearangan, tetapi I Datu Museng tidak dapat mengutarakan isi hatinya dengan baik. Suaranya bergetar dan ucapannya terputus-putus karena sedih. Setelah sang kakek membujuk dengan penuh manja, barulah I Datu Museng angkat bicara. Diceritakannya kepada sang kakek bahwa ia baru saja diusir dari rumah Kadhi Mampawa dan tidak diperkenankan lagi mengaji di tempatnya. Sebenarnya, bukan pengusiran itu yang menyiksa batin ini melainkan akibat dari pengusiran itu. Kini ia tidak dapat lagi melihat bintang kejora di tengah malam, Maipa Deapati, suluh dalam gelap, ratna mutu manikan, permata dalam hayatku.

Mendengar isi hati sang cucu yang sangat tergila-gila kepada I Maipa, Adearangan menasihatinya, seperti dalam kutipan berikut.

"Cucuku, jangan susah karena putri Maipa Deapati bukanlah satu, bukanlah dua, tetapi I Maipa banyak bertebaran di Sumbawa ini dan di sekeliling pulau-pulaunya. Mengapa putri itu menyusahkan hatimu dan membuatmu gundah-gulana? Bukan I Maipa saja yang cantik, bunga setangkai dalam taman. Cucuku, banyak kembang semerbak di berbagai taman. Bintang-bintang di langit juga tak terbilang jumlahnya. Mengapa kau bingung karena I Maipa? ketahuilah, putri Maipa Deapati sudah bertunangan. Ia dijodohkan semasih dalam kandungan Ibundanya dengan I Manggalasa, putra mahkota Sultan Lombok."

Kakek Aderangan menasihati cucunya seperti itu karena tahu persis tentang adat istiadat yang berlaku di tanah Sumbawa. Adat istiadat itu dijunjung tinggi oleh masyarakat Sumbawa, yaitu menganut sistem kasta dan kelompok masyarakat. Menurut hukum adat Sumbawa dua insan yang memiliki pertalian darah yang berbeda dianggap tidak pantas duduk bersanding. Dengan kata lain, salah satu syarat utama untuk memperistri seorang gadis harus mempunyai golongan atau derajat yang sama. Dalam hal ini yang menentukan segalanya adalah golongan darah kebangsawanan dan stratifikasi sosial. Derajat manusia diukur dari segi ketinggian darah kedudukannya di dalam masyarakat. Dengan berdasarkan ketinggian adat tersebut, I Datu Museng akan amat susah dan teramat rumit melamar secara resmi I Maipa. Sebab, Maipa Deapati berdarah bangsawan turunan Sultan yang memerintah, sedangkan I Datu Museng hanya separuh turunan bangsawan. Darah keduanya tidak semurni sehingga tidak pantas duduk bersanding menurut ukuran adat.

Seperti yang terpapar dengan jelas dalam Sinrilik Datu Museng dan Maipa Deapati, hasrat ataupun keinginan agar keberadaan Datu Museng dapat diakui oleh khalayak ramai meskipun darah Datu Museng tidak tulen, serta penghormatan ataupun penghargaan atas cintanya pada Maipa Deapati meskipun tradisi melarang.

Perjuangan Datu Museng untuk mendapatkan pengakuan atas cintanya terhadap Maipa Deapati membutuhkan pengorbanan yang sangat besar. Dia harus pergi jauh menuntut ilmu untuk merasa pantas dan layak disejajarkan dengan Maipa Deapati yang merupakan anak seorang sultan Sumbawa.

Secara implisit didalam cerita, terungkap hasrat atau keinginan agar Datu Museng dipandang layak menjadi pendamping Maipa Deapati dan harusnya dihargai atas semua cinta yang dia miliki serta tidak ingin menyia-nyiakan cinta yang dia miliki. Pengakuan atas cintanya inilah yang menjadi motif perjuangannya mendapatkan cinta Maipa Deapati termasuk meninggalkan kampung halaman 
untuk menuntut ilmu di Mekkah dan Madinah demi tercapainya keinginan tersebut seperti yang termaktub dalam kutipan di bawah.

Dengan suara pasti Datu Museng berkata: "Hanya ke Mekkah dan Medina Kek? Cuma mengarungi laut berombakkan air, menjelajah Sahara berpadangkan pasir? Tak usah kuatir, ke laut api sekali pun aku akan pergi, demi mendapatkan mutiara hidupku. Aku akan pergi menghadang laut marabahaya, akan melintas lautan berombak setinggi rumah. Aku akan menjelajah padang pasir yang terik membara membakar jagat. Keras hatiku kek, kuat tebal keyakinanku. Maipa...Maipaku terbayang di ruang mataku, senyumnya bersemayam dalam jiwaku selalu. Aku akan pergi, pasti...!" Mula pertama ketika pandangan Datu Museng menatap wajah Maipa Deapati yang laksana bidadari itu, di dada anak muda ini langsung menyala bara hangat yang membakar piala hatinya dan menggetarkan seluruh jalur syarafnya. (DM \& MD, 1988: 7)

Dia tidak rela Maipa dimiliki oleh siapapun kecuali dirinya, bahkan ia marah ketika Maipa akan bertunangan dengan I Manggalasa yang telah dijodohkan oleh kedua orang tua Maipa.

Mendengar tutur kakeknya, Datu Museng mendengus menyentakkan kaki. Gerahamnya gemertak menahan marah, matanya mendelik liar. Ia lalu berdiri berkacak pinggang, sambil berkata:

Tidak....tidak...tidak, kakek.....Maipa Deapati adalah Maipaku. I Mangngalasa boleh dijodohkan dengan Maipa sejak kecil, semasih dalam kandungan permaisuri. Tapi sekarang... aku yang punya Maipaku, tunangan Datu Museng I Baso Mallarangang. I Mangngalasa boleh memetik kembang-kembang di taman, boleh bebas memilih bintang di langit biru, tapi ia tak boleh menjamah perawan yang satu ini. I Manggalasa boleh menumpuk harapannya setinggi gunung, tapi tak akan bisa mendapatkannya semasih aku hidup, selagi hayatku di kandung badan (DM \& MD, 1988: 5-6)

Bahkan, untuk pengakuan tersebut, Datu Museng digambarkan rela melakukan apa saja, termasuk meminta bantuan kepada selain Tuhan yang harusnya menjadi tempat bersandar satusatunya. Berikut kutipannya:

Pada tengah malam sunyi itu ia berada dalam biliknya sedang bersemedi menjalankan tapa cipta menyeru ke alam sunyi untuk pengujud cita dimaksud. Ia minta bantuan raja penguasa angin, penguasa guruh dan kilat supaya datang menggelapkan malam memusnahkan suluh beratus-ratus itu, menggetarkan hati dan menakut-nakuti rakyat yang mengawal Maipa Deapati kekasihnya.

(DM \& MD, 1988: 34)

Perjuangannya mendapatkan cinta Maipa Deapati mendatangkan hasil karena ternyata Maipa Deapati pun rela menanggalkan segala gelar dan tradisi yang selama ini menjadi penghalang bagi cinta mereka berdua. Pengakuan atas cinta keduanya pun harus diawali dengan tentangan dari keluarga Maipa Deapati.

Sayangnya, setelah berhasil merubuhkan tembok-tembok tradisi yang membuat aturan tak tertulis tentang siapa saja yang boleh menikahi perempuan turunan sultan, perjuangan keras yang dilakukan untuk benar-benar memiliki Maipa Deapati mendapat lagi perlawanan ketika Maipa Deapati dibawa ke Makassar, tanah kelahirannya. Penguasa Makassar juga mempunyai hasrat untuk menjadikan Maipa Deapati sebagai istri. Tekanantekanan atas segala cinta yang dia miliki terhadap Maipa Deapati dan masalah pengkhianatan yang harus diselesaikan oleh Datu Museng menjadikan Datu Museng menampakkan gejala kelainan jiwa. Gejala kelainan jiwa ini merujuk pada kondisi batin Datu Museng yang oleh karena depresi maka ia mengajak Maipa Deapati untuk mengakhiri hidup, seperti kutipan berikut.

Adinda sayang.....jika sudah kuat kukuh hati dan keyakinanmu, mari relakan dirimu mati. Karena dengan jalan itulah baru kita sampai ke seberang, ke tempat alam abadi. (DM \& MD, 1988:114)

Padahal, tanpa membunuh istrinya pun, Datu Museng tetap bisa mendapat pengakuan dari khalayak betapa dia sangat mencintai istrinya dan betapa ketangguhan ilmu yang dimilikinya 
dapat digunakan untuk mempertahankan istrinya di sampingnya dan untuk menyelesaikan pengkhianatan salah satu orang kepercayaan Maggauka mertuanya di Makassar. Namun, karena merasa tertekan dengan kondisi sekitar mereka yang tidak kondusif, akhirnya Datu Museng memutuskan agar cinta mereka diabadikan dalam kehidupan setelah mati. Gejala jiwa ini muncul karena adanya kepentingan dari berbagai pihak yang terlibat. Konsekuensi logis dari dunia yang bersifat materialistis juga menjadi motivator Datu Museng melakukan tindakan tersebut. Konsep cinta yang dimiliki Datu Museng berdasarkan cerita adalah bahwa mencintai berarti harus memiliki, tidak peduli harus dengan melakukan apapun, bahkan untuk mengorbankan nyawa sekalipun Datu Museng akan melakukannya. Dan makna memiliki pun tidak hanya sebatas bahwa seluruh sudut hati Maipa deapati hanya diisi oleh Datu Museng seorang tapi harta materil dan immateril Maipa deapati pun harus dimiliki. Karena harta materil yang kemudian menjadi bukti bahwa Maipa Deapati benar-benar merupakan milik Datu Museng seutuhnya.

\section{Sinrilik I Datu Museng dan Fungsinya}

Parawansa (1984) mengatakan bahwa Sinrilik I

Datu Museng dan Maipa Deapati merupakan sinrilik yang paling populer di antara sekian sinrilik yang dimiliki oleh masyarakat Makassar. Berdasarkan teks dan peristiwanya, cerita sinrilik ini berlangsung pada abad ke-17.

Pada awalnya, sinrilik I Datu Museng dan Maipa Deapati berasal dari versi lisan, kemudian berkembang dalam bentuk tulisan. Dr. B. F. Matthes adalah orang pertama yang membukukan (menulis) sinrilik I Datu Museng dalam bukunya Makassarsche Chrestomathie tahun 1860 dengan judul Datoe Moeseng. Selanjutnya, dari bentuk teks tertulis itu kemudian terjadi transformasi ke bentuk lain, yaitu dari bentuk teks tertulis ke bentuk roman, drama, dan sinetron. Verdy R. Baso menulis roman yang berjudul I Datu Museng dan Maipa Deapati. Kemudian, Fahmi Syarif menampilkan cerita ini dalam bentuk drama dan sinetron dengan judul $I$ Datu Museng dan Maipa Deapati.

Sampai saat ini sinrilik I Datu Museng masih bertahan dan populer di Sulawesi Selatan. Bertahannya cerita ini tidak terlepas dari nilai dan fungsi yang terdapat dalam sinrilik tersebut. Dalam sinrilik I Datu Museng diperlihatkan perpaduan antara dunia imajiner dan dunia nyata yang ada di sekelilingnya. Dengan demikian, sinrilik secara tidak langsung telah melestarikan nilai-nilai yang terdapat di sekitarnya. Teeuw (1984) mengatakan bahwa dunia nyata dan dunia rekaan merupakan perbedaan yang selalu terdapat dalam karya sastra, termasuk sastra lisan. Dunia nyata dan dunia rekaan selalu saling berkaitan, yang satu tidak bermakna tanpa yang lain. Hubungan yang selalu terjalin antara dunia nyata dan dunia rekaan, memperlihatkan bahwa karya sastra selalu mempunyai fungsi bagi masyarakat pendukung karya sastra itu. Tujuan dan fungsi karya sastra lisan dapat diketahui dengan jalan melihat hubungannya dengan kepercayaan, agama, pengalaman, dan lambang-lambang khusus yang bersifat lokal.

\section{Saudara pendengar,}

Di dalam sinrilik I Datu Museng terdapat hal-hal yang benar-benar ada di dalam masyarakat Sulawesi Selatan. Hal yang dikemukaan dalam cerita tersebut sampai sekarang masih dapat ditelusuri keberadaannya di dalam masyarakat. Fakta-fakta yang terdapat dalam cerita, seperti nama tokoh maupun tempat peristiwa sampai saat ini masih bisa ditemukan di Makassar. Fakta tersebut bisa dilihat dengan diabadikannya tokoh I Maipa Deapati dan Datu Museng sebagai nama jalan ataupun nama sekolah yang tedapat di daerah ini. Fakta cerita pun bisa dilihat dengan kuburan Maipa maupun Datu Museng yang terletak di jalan Maipa dan Datu Museng. Nama-nama tempat seperti Galesong, Kampung Beru, Ujung Tanah dan Mariso memang terdapat di Sulawesi Selatan. Dengan demikian, pasinrilik mampu memadukan dunia nyata dan dunia rekaan (penambahan unsur kiasan maupun fantasi) ke dalam sinrilik I Datu Museng sehingga cerita yang disampaikan seolah-olah terbayang dan hidup kembali di dalam diri penikmat atau pendengarnya.

Fungsi sinrilik I Datu Museng dapat dibagi dalam dua golongan, yaitu fungsi keindahan dan fungsi pengetahuan. Fungsi keindahan yang terdapat dalam cerita dapat dinikmati melalui perpaduan yang harmonis antara cerita yang dilagukan dan alat musik sederhana yang mengiringi pertunjukan. Begitu pula gerak-gerik yang diperlihatkan oleh pasinrilik pada saat menyampaikan ceritanya. Fungsi keindahan lainnya yang terdapat dalam cerita sinrilik I Datu Museng dipaparkan melalui konsep keindahan seorang wanita (Maipa Deapati).

Fungsi pengetahuan yang terdapat dalam 
sinrilik I Datu Museng, terlihat melalui nilai-nilai ajaran agama yang memberi pengetahuan kepada penikmatnya. Di dalam teks tersebut termuat ajaran agama, khususnya agama Islam. Nuansa Islam dipadukan dengan nilai budaya Makassar, yakni sirik (pembelaan terhadap rasa malu dan harga diri) akibat penjajahan Belanda.

\section{PENUTUP}

Sinkretisasi yang dimaksud di sini menyangkut dua sistem prinsip yang berbeda, yakni Islam dan pra-Islam. Secara sederhana yang dimaksud dengan prinsip atau pandangan hidup orang Makassar praIslam di sini adalah keseluruhan perangkat nilai, pandangan hidup, aturan, dan pengetahuan yang dianut oleh orang Makassar sebelum diterimanya prinsip-prinsip ajaran Islam sebagai pedoman bagi kehidupan sebagian besar orang Makassar, atau diterimanya ajaran-ajaran Islam sebagai perangkat pandangan hidup.

Oleh karena sinkretisasi ini selalu mengenai prinsip-prinsip, ajaran-ajaran atau pemikiranpemikiran serta proses penyatuan yang terdapat di dalamnya, fokus pembahasan kita kali ini berada pada tingkat penafsiran atau simbolisasi prinsipprinsip atau ajaran yang ada karena sebenarnya proses sinkretisme ini terjadi pada tingkat tersebut.

Bagi peminat dan pemerhati budaya Makassar, hasil penelitian ini diharapkan dapat menambah wawasan dan pengetahuan mengenai bu-daya Makassar. Pemaparan dan pengungkapan berbagai makna dalam konteks sistem tradisi atau adat-istiadat dan konsepsi kultural yang ter-dapat dalam keempat teks cerita sinrilik yang dikaji, dapat dijadikan sebagai landasan untuk memahami manusia dan budaya Makassar. Kalau peminat dan pemerhati budaya dari etnis lain ingin mengetahui dan me-mahami manusia dan budaya Makassar, maka hasil penelitian ini patut dijadikan sebagai salah satu sumber rujukan.

\section{UCAPAN TERIMA KASIH}

Terimakasi Penulis ucapkan kepada Tim Redaksi Al-Qalam yang telah memberikan ruang untuk terbitnya tulisan ini. Kepada rekan-rekan dosen terima kasih atas masukan yang berbentuk kritikan sehingga tulisan ini dapat diselesaikan dan semoga tulisan ini dapat menjadi acuan meskipun disadari oleh penulis masih terdapat banyak kekurangan.

\section{DAFTAR PUSTAKA}

Arief, Aburaerah dan Zainuddin Hakim (Eds.). 1993. Sastra Lisan Makassar: Sinrilikna Kappalak Tallumbatua. Jakarta: Yayasan Obor Indonesia.

Bahrum, Shaifuddin dan Indriati Lewa. 1996. Datu Museng dan Maipa Deapati. dalam Nurhayati Rahman dan Sri Sukesi Adiwinata (Penyunting). Antologi Sastra Daerah Nusantara. Jakarta: Masyarakat Pernaskahan Nusantara-Yayasan Obor Indonesia.

Basang, Djirong dan Salmah Djirong. 1997. Taman Sastra Makassar. Ujung Pandang: CV Surya Agung.

Mangunwijaya, Y. B. 2003. Sastra Indonesia di Titik Nadir (Wawancara Eksklusif). Dalam Among Kurnia Ebo (Ed.) Sastra di Titik Nadir: Bunga Rampai Teori Sastra Kontemporer (hlm. 1620). Yogyakarta: Jendela.

Manyambeang, Abd. Kadir. 1998. Lontaraq Riwayaqna Tuanta Salamaka Ri Gowa: Suatu Analisis Rintisan Filolinguistik. Disertasi tidak diterbitkan. Ujung Pandang: PPS UNHAS.

Marbangun Hardjowiraga. 1984 Manusia Jawa, Intidayu Press: Jakarta.

Matthes, B.F. 1985. Beberapa Etika dalam Sastra Makassar. Jakarta: Departemen Pendidikan dan Kebudayaan, Proyek Penerbitan Sastra di Daerah.

Nasruddin. 1998. 'Peranan Paruntuk Kana Makassar', Sawerigading 7/2.

Parawansa, Paturungi, dkk. 1992. Sastra Sinrilik Makassar. Jakarta: Departemen Pendidikan dan Kebudayaan.

Robson, S. O. 1987. 'Pengkajian Sastra-sastra Tradisional Indonesia, Majalah Bahasa dan Sastra Tahun V, Nomor 6.

Teeuw, A. 1988. Sastra dan Ilmu Sastra: Pengantar Teori Sastra. Jakarta: Pustaka JayaGirimukti Pasaka.

Wellek, Rene dan Austin Warren. 1999. Teori Kesusasteraan. Diindonesiakan oleh Melani Budianta. Jakarta: PT Gramedia. 